\title{
Interactive comment on "Chamber simulation on the formation of secondary organic aerosols (SOA) from diesel vehicle exhaust in China" by Wei Deng et al.
}

\section{Wei Deng et al.}

wangxm@gig.ac.cn

Received and published: 26 April 2016

Q: My primary criticism is that this manuscript does little to differentiate itself from previous similar works (e.g., Chirico et al 2010, Gordon et al 2014a andb, Nordin et al 2013, and others), and does not seem to offer much in the way of new information or scientific insight. The authors argue that the value of this manuscript lies in the fact that this is the first such study using Chinese diesel engines, which have fewer pollution controls than modern US and European diesels. I do not find this a compelling argument for publication, as both Gordon et al and Chirico et al conducted nearly identical experiments with diesel vehicles without after treatments such as DOC or DPF.

Reply: Thanks for the comments. China is facing a dilemma in combating air pollu- 
tants from traffic emission. We have much more gasoline vehicles than diesel ones. This would be good to reduce PM emission from motor vehicles. However, in recent years surface ozone pollution is becoming more and more serious in many Chinese megacities. Like the situation in Europe, replacing more gasoline cars with diesel ones in China would certainly benefit ground ozone control. We do not know how much SOA would be formed from diesel exhaust. We must pay attention to this point since OA is already the most abundant component in PM2.5 in most of China cities. As diesel engines in China are mostly homemade, we should take cautions if we use results based on diesels in USA or Europe. In fact, even in USA or Europe, there is only a quite limited number of this kind of chamber simulation. Therefore we think it is necessary to conduct this kind of study in China for diesel vehicles because the engine technology and fuel quality might be quite different. And a large audience, including policy makers, would be interested in the results.

Q: The authors also argue that the higher SOA production observed from their engines compared to Gordon et al and Chirico et al is a significant result. However, this could merely be a result of less dilution of the exhaust in the smog chamber and resultant partitioning during oxidation. Figure 2 shows that the $\mathrm{OA}$ concentration in the chamber after exhaust injection was $50 \mathrm{ug} / \mathrm{mËE} 3$. This means that the chamber had ample POA for SOA to partition into, and oodles of vapor available to oxidize and form SOA. My impression is that previous similar studies worked with much lower POA concentrations, and therefore produced less SOA. The authors have done nothing to convince me that the excess SOA formed in their experiments is the result of higher SOA formation potential of the exhaust rather than higher initial concentrations.

Reply: The dilution ratio was 66-214 (see Table 2 in the revised version) comparable with 160 (Gordon et al., 2014b), and 59-94 for no aftertreatment experiments (Chirico et al., 2010). We agree that higher SOA could be caused by higher POA. What is important that our results revealed lower ratios of SOA/POA. As discussed the in revised manuscript, $\mathrm{POA}$ in our study had much higher $\mathrm{O} / \mathrm{C}$ ratio and less volatility. This can

Printer-friendly version

Discussion paper
Interactive

comment 
partly explain higher initial concentrations and less secondary formation (much more oxidized).

Q: The results presented in the manuscript show that a significant amount of SOA is formed during photo-oxidation of dilute exhaust, and that the OA becomes more oxidized during oxidation. This is not new news - Sage et al showed this exact behavior in ACP in 2008 (albeit with a laboratory-scale diesel engine), and the result has been repeated multiple times with emissions from many sources (gasoline engines, diesel engines, aircraft, etc). While I think the underlying data are sound, and the methods appropriate, simply regurgitating previously-published experiments should not pass muster for publication in ACP. The authors need to show how their study adds substantially to the existing state of knowledge.

Reply: In this study, we investigated the possible SOA precursors, and found that significant glyoxal and methylglyoxal formed during the photochemical aging. We noticed that compared to previous studies, the SOA/POA ratios were lower, which could be caused by the difference in the volatility of emitted organics. To a certain extent, these findings help better understand the atmospheric evolution of diesel exhaust and SOA formation in China. Additionally, whether gasoline or diesel dominates the vehicular OA is still a controversial issue (Gentner et al., 2012; Jathar et al., 2014). In this paper, we estimated the gasoline derived $O A$ and diesel derived $O A$, and found that diesel derived OA dominated over gasoline derived OA in China. We also observed the degradation of particle-phase semi-volatiles like PAHs.

Specific comments: - The manuscript needs a thorough English grammar check.

Reply: The language of the revised manuscript has been edited by a native English speaker.

Printer-friendly version

- Is Figure 1 comparing apples to apples? E.g., does it compare the $\mathrm{w}=0$ case from the present study to $\mathrm{w}=0$ from previous work (or $\mathrm{w}=1$ to $\mathrm{w}=1$ )? 
Reply: The EFs/PFs in the present study and in previous works were all compared at $\omega=1$ case.

- Line 330-333: Increase in $\mathrm{m} / \mathrm{z} 59$ during oxidation could also be acetone

Reply: Acetone is mainly biogenic (Jacob et al., 2002), or produced via oxidation of C3-C5 isoalkanes (Fu et al., 2008). We measured the VOCs offline and list in Table 1. During the chamber experiments, the mixing ratios of C3-C5 alkane were only 1-2 ppbv, therefore, the signal of $\mathrm{m} / \mathrm{z} 59$ is mainly glyoxal. (Lines 347-350 in the revised manuscript).

- Figure 4 - which line goes with which axis?

Reply: Revised as suggested.

- The authors only seem to use experiment 8 for representative data. This makes me wary about results from the other experiments.

Reply: Revised as suggested, more data from other experiments were presented in the revised manuscript.

- Figure $8 \mathrm{a}$ - what does SOA mean? Is this the total OA at the end of the experiment or was SOA separated from POA somehow?

Reply: SOA is the aged OA at the end of the experiment. It has been corrected to "aged OA" in revised manuscript.

- Fig 8b would be better if it showed VK plots for more than one experiment.

Reply: Revised as suggested.

Please also note the supplement to this comment: 
Interactive comment on Atmos. Chem. Phys. Discuss., doi:10.5194/acp-2016-50, 2016.

Interactive comment 